\title{
Spatial and demographic patterns of climate related diseases among hospitalized children in parts of Southwest Nigeria
}

\author{
Aina T. Adeboyejo ${ }^{1}$, David O. Adejumobi ${ }^{1}$, Yemi Adewoyin ${ }^{* 2,3}$, \\ Abisola O. Oyasiji ${ }^{1}$ \\ ${ }^{1}$ Ladoke Akintola University of Technology, Nigeria \\ ${ }^{2}$ University of Nigeria, Nigeria \\ ${ }^{3}$ University of the Witwatersrand, South Africa
}

The health burdens of climate change are spread disproportionately, with developing countries being the most affected. These effects burden children in developing countries. This study assesses the effects of climate change on the health of children in parts of Southwest Nigeria, analyzes inter and intra-city variations in the prevalence of climaterelated diseases among children, and examines the influence of demographic variables on the incidence pattern. Hospital records of 7,458 children and climatic data of three cities were employed. The results show that $58 \%$ of the cases were for female children, while $56 \%$ of the diagnosis was for malaria. Other diseases found included diarrhoea (16\%), meningitis (6\%) and asthma (4\%). Temperature and rainfall accounted for $32.3 \%$ and $44.6 \%$ of the variations in malaria and diarrhoea cases and there were significant inter-city and intra-city variations in the disease incidence. More female children were affected irrespective of their socioeconomic background while $72.2 \%$ of children affected were aged below 5 .

Key Words: spatial variation, climate change, climate related diseases, children's health, Nigeria.

Article Info: Received: February 10, 2020; Revised: April 25, 2020; Accepted: May 12, 2020; Online: May 23, 2020.

\footnotetext{
"Corresponding author

Address: Department of Geography, University of Nigeria, Nsukka - Onitsha Rd, Nsukka, Nigeria.

Phone: +2348062932175| Email: yemiadewoyin@yahoo.com
}

(C)2020 Human Geographies; The authors

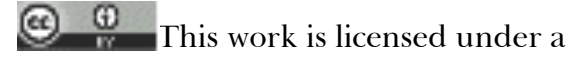

Creative Commons Attribution 4.0 International License. DOI:10.5719/hgeo.2020.141.4 


\section{Introduction}

Climate change affects diverse physical and biological systems worldwide with population health being one of the most threatened. Many developing countries experience a disproportionate share of the effects (Hanna \& Oliva, 2016; Campbell-Lendrum et al, 2015; World Health Organization, 2014). This is mostly due to the fact that developing countries often have limited social safety nets, are characterized by widespread poverty, have fragile health care systems and weak governmental institutions that make it harder for them to adapt or respond to climate change (Hanna \& Oliva, 2016). Children also appear the most vulnerable group of the affected human population because of their physiological and cognitive immaturity which makes them more sensitive than adults to adverse environmental conditions (Hanna \& Oliva, 2016; Sheffield \& Landrigan, 2011; Balbus \& Malina, 2009). Children are potentially much more vulnerable than adults to environmental factors because they are physically weaker and less able to dissipate heat. Of the about 150,000 worldwide deaths attributable to the disease burden of climate change in the year 2000, $88 \%$ fell upon children (Sheffield \& Landrigan, 2011). Approximately one in five deaths around the world each year occurs in children under age five (World Health Organization, 2008), with lower respiratory tract infections, diarrhoea, and malaria responsible for more than 50\% of the deaths (Pruss-Ustan \& Corvalan, 2007). Respiratory diseases, diarrhoea and malaria, are environmental related diseases that are exacerbated by climate change. Children in developing countries are burdened by the health effects of climate change.

Of the several studies conducted on the health impacts of climate change, those focusing on the effects among children and other vulnerable subpopulations are relatively few (Balbus \& Malina, 2009; World Health Organization, 2009; UNICEF, 2015). Much fewer, even, are those with a focus on children in developing countries, particularly Nigeria, where high birth rate and rapid urbanization exert pressure on the environment and exacerbate the impacts of climate change. The birth rate, in particular, ensures that the number of children in the total population is kept high at all times and places this vulnerable cohort in the care of fewer adults whose life expectancy is less than 55. The proportion of children in the Nigerian population is $51 \%$ (National Bureau of Statistics, 2018). This study attempts a review of the impacts of climate change on the health of children in parts of Southwest Nigeria. It, however, differs from other studies on the same subject in several ways. Beyond establishing a relationship between the changes in climatic parameters and the incidence of some climate-related diseases among children in the study area, the study established inter-city and intra-city variations in the prevalence pattern. Equally, it provides explanations on the inter-city and intra-city drivers of the variations observed. The influence of demographic variables of age and sex on the incidence pattern was also examined. Most studies have treated the city as a monolithic entity, ignoring the very obvious variations in urban land-use and socioeconomic patterns in the city. 
The urban poor tend to live in disadvantaged neighbourhoods within the cities with high population density, low income, informal employment and limited public services (Grant, 2010). Many of them live in the worst conditions within the cities (Stephens, 2011). On the other hand, urban elites are connected and often have a selection of homes in the best areas of many global cities (Stephens, 2012). In other words, there is a residential agglomeration within the city that is based on income and socioeconomic status. These variations have been found to influence health outcomes and access to healthcare (Almeida et al., 2017; Franks \& Fiscella, 2002; Ikporukpo, 2002; Andrulis, 2000; Kawachi \& Kennedy, 1997; Okafor, 1982; Wan \& Gray, 1978; Lineberry, 1976; Hart, 1971).

Studies have also shown that there is a gendered disparity in health status (Langlois \& Morrison, 2002; Society for Women's Health Research, 2001; Shaywitz et al., 1995; Makkar et al., 1993). None of these studies, however, investigated the disparity among male and female children, and within the context of where they live in the urban space. The exposures that influence children's health begin before conception and is reflected in parents' diets and other environmental exposures, and continue through pregnancy, childhood, and adolescence (Sheffield \& Landrigan, 2011). Climate-related examples of such exposures include difference in physiology and baseline metabolism, early rapid development that creates windows of vulnerability in early childhood, higher exposures per unit body weight, as well as diet and behaviour (Committee on Sports Medicine and Fitness, 2000; Selevan et al., 2005; Landrigan \& Garg, 2005; Pronczuk-Garbino, 2005). Age thus matters for susceptibility to diseases, and this study investigated at what point in the childhood life course it is mostly affected by variations in climatic parameters in the study area.

\section{Materials and methods}

\section{Study area and sample selection}

Nigeria comprises 36 States and a Federal Capital Territory. Based on contiguity, cultural affiliation and common heritage, these 36 States are grouped into six geopolitical regions: Northwest, Northeast, Northcentral, Southeast, Southsouth and Southwest. The Southwest region, comprising 6 States, was purposively selected for this study. The region is the most urbanized in the country. The region also has a unique geography with respect to vegetation. While the Northern regions are located predominantly in the savannah vegetation belts of the country and the Southern regions located in the forest zones, the Southwest straddles both. This characteristic enables a spatial comparison of events and processes within the region that can be generalized for the entire country. Within the region, three urban centres were further selected. These are Ibadan in the rain forest zone of the region, Ogbomoso in the guinea savannah, and Ile-Ife, a transition city between both belts. The usage of vegetation as a sampling criterion for the study is predicated on the established facts that climatic parameters of 
rainfall and temperature are affected by vegetation. The selected cities also have easily distinguishable residential agglomerations based on socioeconomic status. This permits an analysis of intra-city variations in disease pattern along socioeconomic lines.

\section{Data types}

Two sets of secondary data were employed for this study. The first was on climaterelated diseases (CRD) and the demographic data of the affected patients while the second was on climatic parameters of temperature and rainfall. The first data set relates to the incidence of such diseases as malaria, diarrhoea, meningitis, respiratory infection, measles, asthma, typhoid fever, dengue fever, and yellow fever. The pathogenesis and transmission of these diseases are environmental and are affected by fluctuations in temperature and rainfall. The data also included age, sex and location of the patients as shown by their residential addresses, collected from a review of hospital case notes of 7,458 children aged 0 to 13 over 17 years from 1999 to 2015 . The second type of secondary data employed for the study is the meteorological data for the period 1999 to 2015. Specifically, data on mean maximum temperature (MMT) and mean annual rainfall (MAR) for each of the three selected cities were collected for the 17 years reviewed.

\section{Data sources and analysis}

The data on disease incidence and demographics of the patients were extracted from the records of the University College Hospital (UCH), Ibadan, the Obafemi Awolowo University Teaching Hospital (OAUTH), Ile-Ife, and Bowen Medical Center (BMC), Ogbomoso. The three facilities were purposively selected because they are tertiary hospitals with patronage from all parts of the country. They are the teaching hospitals for the Universities of Ibadan, Obafemi Awolowo University and Bowen University respectively, and provide quality and regular data for government agencies and the ministries of health for national planning. Data obtained from their records are therefore assumed to be of high quality and integrity. The data on the climatic parameters was sourced from the records of the Nigerian Meteorological Agency (NIMET), Lagos.

The data collected on the number of cases of climate-related diseases (CRDs) across the selected cities were analyzed for spatial variations using Analysis of Variance (ANOVA). Pearson's Product Moment Correlation (PPMC) technique was employed for trend analyses of the annual number of cases of the CRDs as well as the temporal trends of temperature and rainfall in the selected cities for the period reviewed. Further, multiple regression analyses were carried out to establish the relationship between fluctuations in the climatic parameters and disease pattern. The regression analyses were carried out on the two most prevalent diseases among hospitalized children for each of the three cities and collectively. While the mean maximum temperature and mean annual rainfall data constituted the independent variables, the number of disease cases was the 
dependent variable. The individual correlation coefficients, from the regression output, between each of the independent variables and the diseases examined, were also employed to describe the individual relationships.

\section{Results}

\section{Trend of climatic parameters in the study area}

The maximum annual rainfall (MAR) volume in the selected cities was lowest in Ogbomoso in 2001 at $58.1 \mathrm{~mm}$ while Ibadan had the highest volumes in 1999 $(151.2 \mathrm{~mm})$ and $2011(148.9 \mathrm{~mm})$. The highest volume recorded in Ogbomoso was $128.3 \mathrm{~mm}$ in 1999 while it was $142.5 \mathrm{~mm}$ in Ile-Ife in 2008 . The driest year was also 2001 in Ile-Ife with $85.5 \mathrm{~mm}$ of rainfall, whereas it was in 2003 in Ibadan with $95.3 \mathrm{~mm}$ of rainfall (Figure 1). The years 2004 and 2015 were the hottest in Ibadan as the city recorded mean maximum temperature (MMT) above $32^{\circ} \mathrm{C}$ in both years. Ile-Ife was hottest in 2010 and 2011 with MMTs of $31.8^{\circ} \mathrm{C}$ while $33.3^{\circ} \mathrm{C}$ in Ogbomoso in 2010 was the city's hottest year in the period of study (Figure 2).

While it appears that the temperature trend in Ogbomoso was declining from 2010 and rising in Ibadan in the same period, an analysis of the trend shows rising temperature in the three cities. The correlation coefficients $(r)$ were $0.37,0.18$ and 0.11 in Ogbomoso, Ibadan and Ile-Ife, respectively. The rainfall pattern also showed a marginal annual increase with correlation coefficients (r) of 0.26, 0.12 and 0.18 for Ogbomoso, Ibadan and Ile-Ife, respectively.

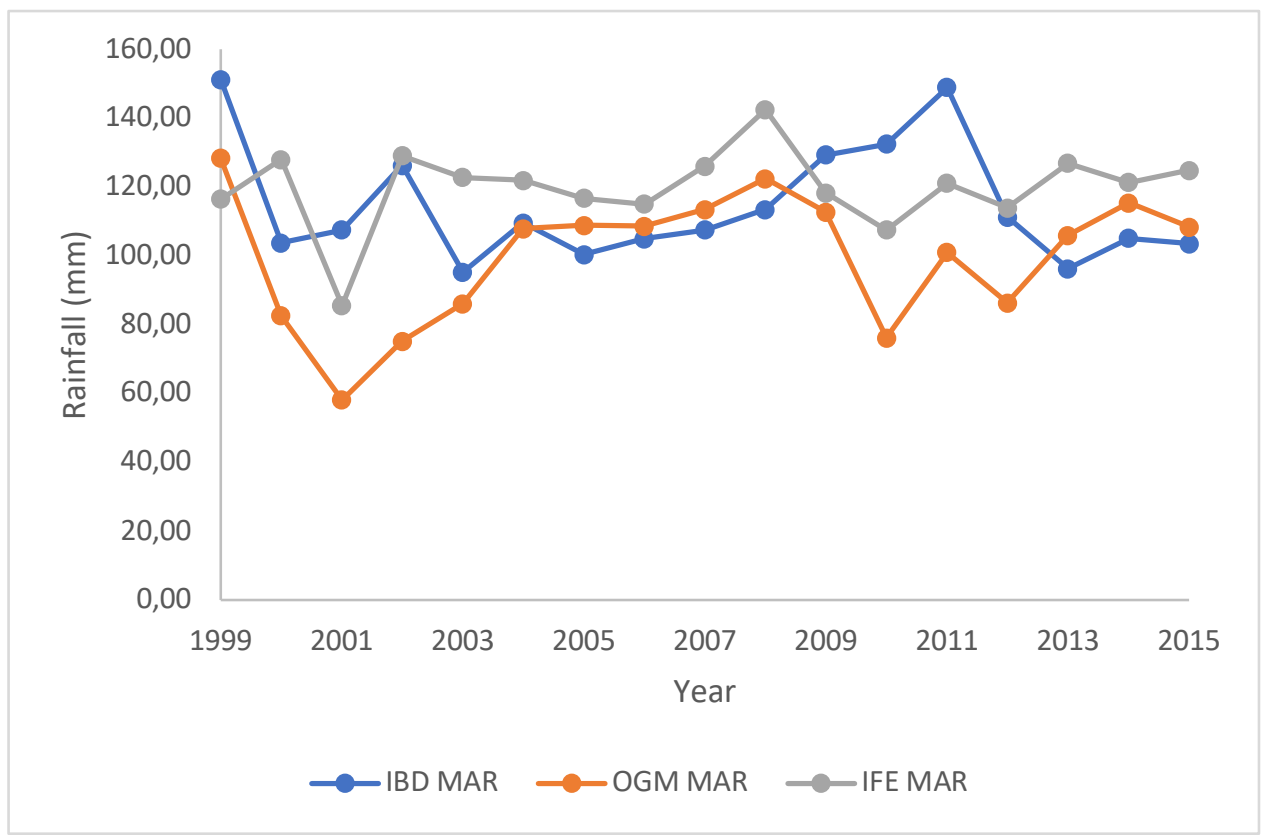

Figure 1. Trend of mean annual rainfall in the study area 


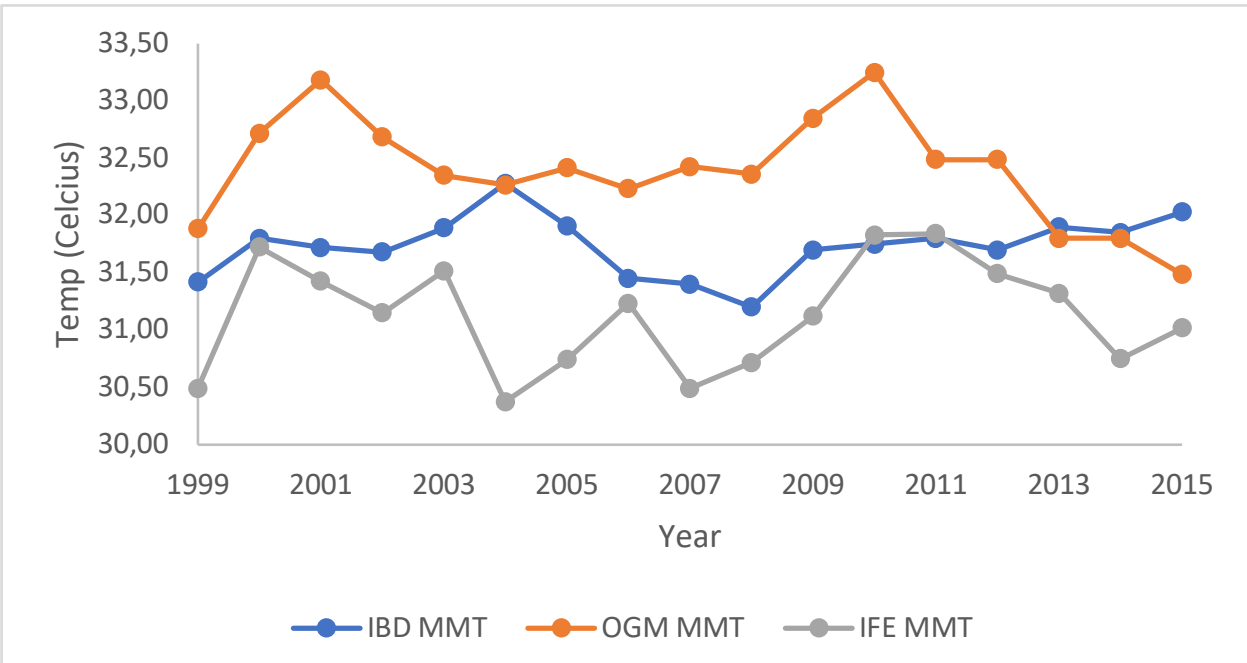

Figure 2. Trend of mean maximum temperature in the study area

\section{Cases and Trend of Diseases}

From the 7,458 case files reviewed, $58 \%$ of the hospitalized children were females while $42 \%$ were male children. From the review, the five most prevalent climaterelated diseases responsible for the hospitalization of the children were malaria (56\%), followed by diarrhoea (16\%), meningitis and respiratory infections $(6 \%$ each), measles (5\%), and asthma (4\%). Typhoid and dengue fever accounted for $3 \%$ each while the proportion of yellow fever cases was $1.0 \%$. The trend analysis of these diseases, illustrated in Figure 3, shows that while malaria had a generally high profile throughout the period, there was a sharp decline in the number of cases in 2003. Further analysis reveals that, the incidence of malaria and diarrhoea, each with correlation coefficient $(r)$ of 0.045 , and meningitis $r=0.179$ increased over the years between 1999 and 2009. However, respiratory infection and measles with negative coefficients of -0.203 and -0.165 showed a declining tendency over the same period.

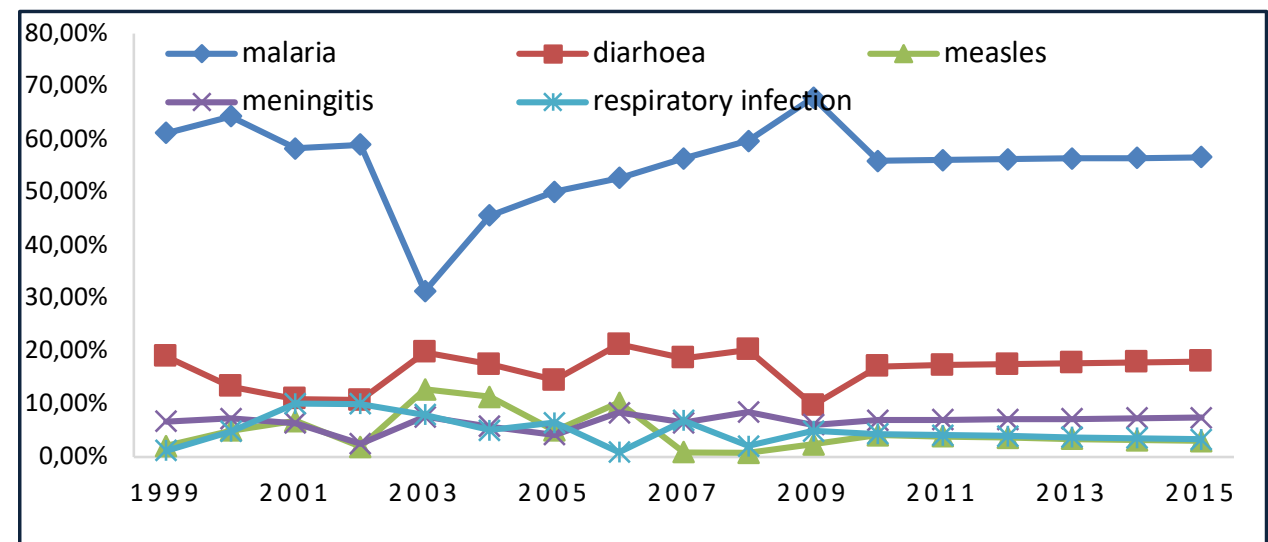

Figure 3. Trend in the incidence of climate-related diseases (1999-2015) 


\section{Spatial variation in diseases incidence}

The inter-city variations in the incidence of diseases, that is the proportional distribution of each disease cases in a particular city relative to the total number of all disease cases in the city, as summarized in Table 1, show that the incidence of malaria was highest in Ogbomoso (64.8\%) in the guinea savannah environment. Malaria also accounted for $53.4 \%$ hospitalization in Ile-Ife and $46.6 \%$ in Ibadan in the rain forest. Cases of diarrhoea $(25.2 \%)$ and meningitis $(7.0 \%)$ were more prevalent in Ile-Ife followed by Ogbomoso and Ibadan. Respiratory infection and asthma were mostly associated with children in Ibadan. Cases of hospitalization for both were $18.6 \%$ and $12.8 \%$ respectively. Ogbomoso had the highest proportion of typhoid (3.7\%) while Ile-Ife recorded the highest proportion of cases of measles $(8 \%)$. The inter-city variation in the prevalence pattern of the disease was analyzed using the Analysis of Variance (ANOVA) statistical technique. The results indicate that there was a statistically significant spatial variation in the number of cases among the three urban centres $(\mathrm{P}<0.001)$. Within the selected cities, the high-density residential areas had the highest incidence of all cases of diseases $(70.7 \%$ ) compared with $21.2 \%$ and $8.1 \%$ for medium and low-density residential areas. This observation was also tested for significance using ANOVA, and the results showed statistical significance in the variations $(\mathrm{P}<0.001)$.

\section{Climate Change and Trend of Diseases}

In analyzing the relationship between the variables of temperature and rainfall and the number of hospital cases of climate-related diseases in this study, eight multiple regression models were employed. The first six were for the two most prevalent diseases in each of the three cities, while the seventh and eighth models were on all cases of malaria and diarrhoea in all the cities together.

Table 1. Inter-city variations in cases of diseases

\begin{tabular}{|c|c|c|c|c|c|c|c|c|c|c|}
\hline : & $\frac{\sqrt[\pi]{J}}{\stackrel{\pi}{Z}}$ & $\begin{array}{l}\mathscr{E} \\
\dot{0} \\
\tilde{D}\end{array}$ & $\begin{array}{l}\frac{7}{0} \\
\frac{\pi}{2} \\
\frac{1}{2}\end{array}$ & $\frac{3}{0}=$ & 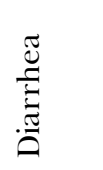 & $\frac{\widetilde{\Xi}}{\Xi}$ & 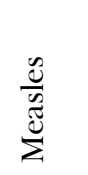 & 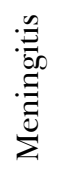 & 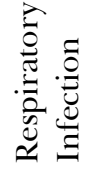 & $\stackrel{\pi}{0}$ \\
\hline \multicolumn{11}{|l|}{ Ibadan } \\
\hline No & 660 & 136 & 17 & 17 & 45 & 181 & 30 & 67 & 264 & 1417 \\
\hline$\%$ & $46.6 \%$ & $9.6 \%$ & $1.2 \%$ & $1.2 \%$ & $3.2 \%$ & $12.8 \%$ & $2.1 \%$ & $4.7 \%$ & $18.6 \%$ & $100.0 \%$ \\
\hline \multicolumn{11}{|l|}{ Ile-Ife } \\
\hline No & 1776 & 0 & 97 & 0 & 838 & 116 & 266 & 233 & 0 & 3326 \\
\hline$\%$ & $53.4 \%$ & $.0 \%$ & $2.9 \%$ & $.0 \%$ & $25.2 \%$ & $3.5 \%$ & $8.0 \%$ & $7.0 \%$ & $.0 \%$ & $100.0 \%$ \\
\hline \multicolumn{11}{|l|}{ Ogbomoso } \\
\hline No & 1759 & 95 & 100 & 19 & 289 & 19 & 109 & 168 & 157 & 2715 \\
\hline$\%$ & $64.8 \%$ & $3.5 \%$ & $3.7 \%$ & $.7 \%$ & $10.6 \%$ & $.7 \%$ & $4.0 \%$ & $6.2 \%$ & $5.8 \%$ & $100.0 \%$ \\
\hline Total no. & 4195 & 231 & 214 & 36 & 1172 & 316 & 405 & 468 & 421 & 7458 \\
\hline Total \% & $56.2 \%$ & $3.1 \%$ & $2.9 \%$ & $.5 \%$ & $15.7 \%$ & $4.3 \%$ & $5.4 \%$ & $6.3 \%$ & $5.6 \%$ & $100.0 \%$ \\
\hline
\end{tabular}


The regression results show that fluctuations in rainfall and temperature accounted for $37.8 \%, 28.6 \%$ and $42.1 \%$ of the variations in the number of malaria cases among hospitalized children in Ogbomoso, Ibadan and Ile-Ife respectively. The coefficients of determination between the climatic parameters and diarrhoea were $0.576,0.426$ and 0.314 in Ogbomoso, Ibadan and Ile-Ife, respectively. This implies that in the three cities, climate change accounted for $57.6 \%, 42.6 \%$ and $31.4 \%$ of the variations in the incidence of diarrhoea among the study population. When the cases were aggregated by combining the number of cases for malaria in the three cities of study, the result $(\mathrm{R} 2=0.323, \mathrm{P}<0.01)$ shows that fluctuations in temperature and rainfall were responsible for $32.3 \%$ of malaria hospitalization in the study area. For diarrhoea cases, the percentage of variance predicted by rainfall and temperature was $44.6 \%$. The value was, however, not statistically significant.

At the individual levels and using the partial correlation results of the regression output, malaria and diarrhoea were positively correlated with temperature $(r=0.43, r=0.37$ respectively) in Ogbomoso. While the relationship was significant $(\mathrm{P}<0.005)$ for malaria, it was not significant in the case of diarrhoea. The relationship between malaria and rainfall $(\mathrm{r}=0.56)$, and diarrhoea and rainfall $(\mathrm{r}=0.76)$ were both significant at $\mathrm{P}<0.005$. The results in Ibadan were not largely different. While malaria and temperature recorded a significant positive correlation $(\mathrm{r}=0.63, \mathrm{P}<0.005)$, diarrhoea also had a positive correlation with temperature, though statistically insignificant $(\mathrm{r}=0.25, \mathrm{P}>0.005)$. It did, however, highly correlate with rainfall and statistically significant $(r=0.65$, $\mathrm{P}<0.005)$. Malaria cases in Ibadan were also positively correlated with rainfall $(\mathrm{r}=0.71)$. The relationship was also statistically significant. Cases of malaria and diarrhoea also recorded a positive correlation with rainfall in Ile-Ife, and both were statistically significant $(r=0.63, r=0.56$ respectively). While cases of malaria in Ile-Ife were highly correlated with temperature $(\mathrm{r}=0.79, \mathrm{P}<0.005)$, fluctuations in the mean maximum temperature in Ile-Ife had no strong relationship with diarrhoea cases in the city $(\mathrm{r}=0.18, \mathrm{P}>0.005)$.

\section{Gender and age differentials in disease incidence}

The reviewed hospital records showed that female children $(58 \%)$ were more affected compared to their male counterpart (42\%). This observation shows no significant variations among the residential areas as more female than male were affected in the high density (57.3\%), the medium (55.0\%) and low-density residential areas $(54.0 \%)$. This study identified critical ages at which children are more susceptible as 0 to 1 year $(42.5 \%)$. This was followed by age 1 to 2 years (18.7 $\%$ ), and 3 to 5years $(11 \%)$. The result showed a rising trend in the incidence of diseases from the first month up to 1 year, before a decline from age 2 as illustrated in Figure 4. 


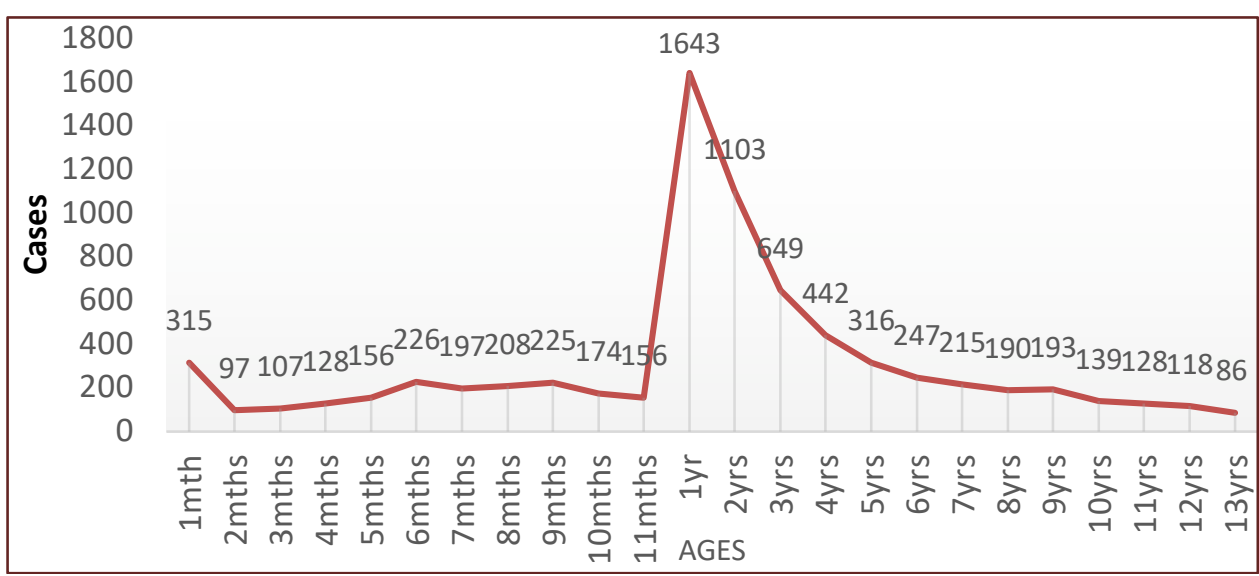

Figure 4. Age-specific variation in disease incidence

Further statistical examination of the relationship between specific ages of children and the incidence of diseases reveals a negative correlation $(r=-0.21$, $\mathrm{P}>0.005)$. This implies that there is an inverse relationship between age and incidence of disease. That is, the older the children, the lower the incidence of disease. The result also showed that between birth and one month, the number of cases of CRDs was higher than any other month before the children attained age 1 .

\section{Discussions}

The results showed that cases of malaria were more prevalent in the study area than any other climate-related diseases, and its incidence showed a low but steady increment throughout the study. Cases of diarrhoea, meningitis, measles, asthma, other respiratory infections, typhoid and dengue fever, were also observed as being prevalent in the study area. Across the cities, Ogbomoso recorded the highest cases of malaria, typhoid, yellow fever and measles. Ile-Ife had fewer cases of malaria, typhoid and measles than Ogbomoso but more cases than Ibadan. With respect to diarrhoea, Ile-Ife had the highest number of cases. It was followed by Ogbomoso and Ibadan, which recorded the lowest number of cases. Ile-Ife also had the highest number of meningitis cases, while cases of asthma and other respiratory infections were highest in Ibadan.

The temperature and rainfall patterns in the three cities were found to significantly account for the variations in and positively correlated with the diseases examined in particularly malaria. These confirm earlier findings that climatic factors play essential roles in the prevalence of malaria globally (Zacarias \& Andersson, 2011; Caminade et al., 2014), and in Nigeria in particular (Oluleye \& Akinbobola, 2010; Efe \& Ojoh, 2013), and the incidence of diarrhoea, meningitis, measles, asthma, typhoid and dengue fever in children and older adults (Adeboyejo et al., 2012; Adeboyejo \& Adewoyin, 2017). 
Ogbomoso is located in the guinea savannah vegetation belt and is the driest of the three cities in temperature and rainfall. It was hotter than the other cities and recorded lower precipitation volumes. The literature is replete with evidence that hot temperature shortens mosquito's breeding cycle and speeds its reproduction rate while also lengthening the season during which mosquito abounds. The hot temperature increases the reproduction rate of the parasites and thus increases the likelihood that a single bite will cause malaria infection. Measles and both febrile illnesses of typhoid and yellow fever are also diseases that are largely temperature-dependent. The consumption of contaminated water is a major cause of diarrhoea. While the volume of rainfall in Ibadan was higher than those of Ile-Ife and Ogbomoso, the relatively lower cases of diarrhoea in Ibadan compared to Ile-Ife and Ogbomoso might not be unconnected with the sources of water in the city. Most households in Ibadan rely on water from treated wells, boreholes and other commercial sources of treated water while in the other cities some residential neighbourhoods have no access to treated water sources and still source water from open wells, streams and rivers. Ibadan is also the most industrialized of the three cities and has a lot of water processing factories to complement the several industrial water processing plants. Perhaps it is the same industrialized status that accounted for why the city ranked highest in terms of asthma cases and other respiratory infections. Industrial smokes, cold and dampness are triggers for asthma and most respiratory diseases.

The intra-city variation in the incidence of diseases observed, such that highdensity residential neighbourhoods had the highest number of cases while the low-density areas recorded the lowest number of cases, confirms findings from other studies on the spatial agglomeration of diseases based on socioeconomic status and places of residence (Hart, 1971; Wan \& Gray, 1978; Kawachi \& Kennedy, 1997; Andrulis, 2000; Franks \& Fiscella, 2002). The high-density areas are characterized by high population density, low income, informal employment, limited public services and poor infrastructure. All these negatively affect their sanitation and health-seeking behaviour. This finding implies that 7 out of 10 children with CRDs lived in the high-density residential area where the low socioeconomic group in the society is found and that there is a relationship between the socioeconomic background of children and vulnerability to climate change diseases (Balbus \& Malina, 2009; Sheffield \& Landrigan, 2011; Hanna \& Oliva, 2016). The results also showed that more female children were more affected by CRDs than their male counterparts.

This finding among children suggests that gendered disparity in health outcomes among adult females and males, as established in the literature (Langlois \& Morrison, 2002; Society for Women's Health Research, 2001; Shaywitz et al., 1995; Makkar et al., 1993), may have started from infancy. The disparity is observed across the three cities and the different residential areas of each city. This suggests that biology and genetics, rather than socioeconomic background and environmental factors, are plausible explanations for health disparity between female and male children. The study also shows that majority of children affected by CRDs are those below age 5 in line with a World Health 
Organization report (UNICEF, 2015), with a peak around age 1. This is largely due to their physiological and cognitive immaturity, which makes them more vulnerable to exposure to environmental conditions promoting ill-health (Selevan et al., 2005; Landrigan \& Garg, 2005).

\section{Conclusion}

The study has shown that variations in climatic parameters of temperature and rainfall have profound adverse effects on the incidence and prevalence of environmentally-dependent diseases like malaria, diarrhoea, meningitis and asthma among children. The incidence of these diseases in the study area was also found to vary among cities and within cities. Within the city, high-density residential areas, populated mostly by people of low socioeconomic class, recorded the highest number of cases with 7 out 10 cases (children) coming from there. More female children were also found to suffer more climate-related diseases than their male counterparts irrespective of their socioeconomic background while children under age 5 were mostly affected. Policies and practices to address the health effects of climate change on the population should take cognizance of the locational characteristics of places, gender and age for them to achieve meaningful outcomes.

\section{Acknowledgement}

We acknowledge the management and staff of the University College Hospital (UCH), Ibadan, Obafemi Awolowo University Teaching Hospital (OAUTH), IleIfe, and Bowen Medical Center (BMC), Ogbomoso for granting us access to clinical records and for their cooperation during the data collection process.

\section{References}

Adeboyejo, A.T. and Adewoyin, Y. (2017), "Climate Change and Health of the Aged in Lagos, Nigeria", Australian Journal of Basic and Applied Science, vol. 11, no. 13 , p. 8-16.

Adeboyejo, A.T, Lirvhuwani, M. and Shonisani, D.K. (2012), "Impact of Climate Change on Children's Health in Limpopo Province, South-Africa", International Journal of Environmental Research and Public Health, vol. 9, no. 3, p. 831-854

Almeida, A.P., Nunes, P.B., Duro, S.M.S. and Facchini, L.A. (2017), "Socioeconomic Determinants of Access to Health Services among Older Adults: A Systematic Review", Revista de Saude Publica, vol. 51.

Andrulis, D.P. (2000), "Community, Service, and Policy Strategies to Improve Health Care Access in the Changing Urban Environment", American Journal of Public Health, vol. 90, p. 858-862. 
Balbus, J.M. and Malina, C. (2009), "Identifying Vulnerable Subpopulations for Climate Change Health Effects in the United States", Journal of Occupational and Environmental Medicine, vol. 51, no. 1, p. 33-37

Caminade, C., Kovats, S., Rocklov, J., Tompkins, A.M., Morse, A.P., ColónGonzález, F.J., Stenlund, H., Martens, P. and Lloyd, S.J. (2014), Impact of Climate Change on Global Malaria Distribution, Potsdam Institute for Climate Impact Research, Potsdam, Germany.

Campbell-Lendrum, D., Manga, L., Bagayoko, M. and Sommerfield, J. (2015), "Climate Change and Vector-Borne Diseases: What are the Implications for Public Health Research and Policy?", Philosophical Transactions of the Royal Society B: Biological Sciences, vol. 370, no. 1665.

Committee on Sports Medicine and Fitness (2000), "Climatic Heat Stress and the Exercising Child and Adolescent: American Academy of Pediatrics Policy statement", Pediatrics, vol. 106, p. 158-159.

Efe, S.I. and Ojoh, C.O. (2013), "Climate Variation and Malaria Prevalence in Warri Metropolis", Atmospheric and Climate Sciences, vol. 3, p. 132-140.

Franks, P. and Fiscella, K. (2002), "Effect of Patient Socioeconomic Status on Physician Profiles for Prevention, Disease Management, and Diagnostic Testing Costs", Medical Care, vol. 40, no. 8, p. 717-24.

Grant, U. (2010), "Spatial Inequality and Urban Poverty Traps", Working Paper 326, Overseas Development Institute, London.

Hanna, R. and Oliva, P. (2016), "Implications of Climate Change for Children in Developing Countries", The Future of Children, vol. 26, no. 1, p. 115-32.

Hart, J.T. (1971), "The Inverse Care Law", Lancet, vol. 1, p. 405-412.

Ikporukpo, C.O. (2002), Spatial Engineering and Accessibility. An Inaugural Lecture, University of Ibadan, Nigeria, Vantage Publishers, Ibadan.

Kawachi, I. and Kennedy, B.P. (1997), "Socio-Economic Determinant of Health: health and social cohesion, why care about income inequality?", British Medical Journal, vol. 314, no. 7086, p. 1037-1040.

Landrigan, P.J. and Garg, A. (2005), "Children are Not Little Adults" in J. Pronczuk-Garbino (ed.), Children's Health and the Environment - A Global Perspective: A Resource Manual for the Health Sector, World Health Organization, Geneva, Switzerland, p. 3-16.

Langlois, S. and Morrison, P. (2002), "Suicide Deaths and Suicide Attempts", Health Reports, Statistics Canada, Catalogue 82-003, p. 9-22.

Lineberry, R. (1976), "Equality, Public Policy and Public Services: The Underclass Hypothesis and the Limits to Equality", Policy and Politics, vol. 4, no. 2, p. 67-84. Makkar, R.R., Fromm, B.S., Steinman, R.T., Meissner, M.D. and Lehmann, M.H. (1993), "Female Gender as a Risk Factor for Torsades de Pointes Associated with Cardiovascular Drugs", Journal of the American Medical Association, vol. 270, no. 2, p. 2590-2597.

National Bureau of Statistics (2018), 2017 Demographic Statistics Bulletin, National Bureau of Statistics, Abuja.

Okafor, S.I. (1982), "Policy and Practice: The Case of Medical Facilities in Nigeria", Social Science E Medicine, vol. 16, no. 22, p. 1971-1977. 
Oluleye, A. and Akinbobola, A. (2010), "Malaria and Pneumonia Occurrence in Lagos, Nigeria: Role of Temperature and Rainfall", African Journal of Environmental Science and Technology, vol. 4, no. 8, p. 506-516.

Pronczuk-Garbino, J. (2005), Children's Health and the Environment - A Global Perspective: A Resource Manual for the Health Sector, World Health Organization, Geneva, Switzerland.

Pruss-Ustan, A. and Corvalan, C. (2007), "How Much Disease Burden can be Prevented by Environmental Intervention?", Epidemiology, vol. 18, no. 1, p. 167178.

Selevan, S.G., Kimmel, C.A. and Mendola, P. (2005), "Windows of Susceptibility to Environmental Exposures in Children", in J. Pronczuk-Garbino (ed,) Children's Health and the Environment - A Global Perspective: A Resource Manual for the Health Sector, World Health Organization, Geneva, Switzerland, p. 17-26.

Shaywitz, B.A., Shaywltz, S.E., Pugh, K.R., Constable, R.T., Skudlarski, P., Fulbright, R.K., Bronen, R.A., Fletcher, J.M., Shankweiler, D.P., Katz, L. and Gore, J.C. (1995), "Sex Differences in the Functional Organization of the Brain for Language", Nature, vol. 373, p. 607-609.

Sheffield, P.E. and Landrigan, P.J. (2011), "Global Climate Change and Children's Health: Threats and Strategies for Prevention", Environmental Health Perspective, vol. 119, no. 3, p. 291-298.

Society for Women's Health Research (2001), Women and Men: 10 Differences that Make a Difference, 16 May 2010, shorturl.at/nsBIK.

Stephens, C. (2011), "Revisiting urban health and social inequalities: the devil is in the detail and the solution is in all of us", Environment and Urbanization, vol. 23, no. 1, p. 29-40.

United Nations Children's Fund (UNICEF) (2015), Unless We Act Now: The Impact of Climate Change on Children, United Nations, New York.

Wan, T.T.H. and Gray, L.C. (1978), "Differential Access to Preventive Services for Young Children in Low-Income Urban Areas", Journal of Health and Social Behaviour, vol. 19, p. 312-324.

World Health Organization (WHO) (2008), The Global Burden of Disease: 2004 Update, World Health Organization, Geneva.

World Health Organization (WHO) (2009), Protecting Health from Climate Change: Global Research Priorities, 15 February 2011, shorturl.at/rEVWZ.

World Health Organization (WHO) (2014), Climate Change and Health Projects, Geneva, Switzerland.

Zacarias, O.P. and Andersson, M. (2011), "Spatial and Temporal Patterns of Malaria Incidence in Mozambique", Malaria Journal, vol. 10, no. 189. 